existing inflammatory adhesions binding the uterus down in the pelvis, and rendering replacement impossible. Abortion or diminution of the bulk of the uterus is here the only means of relief. I suspect these cases are not uncommon. I have met with several instances of procidentia and prolapsus in the unimpregnated, in which elevation of the uterus beyond a short distance from the vulva was impossible. If pregnancy occur in such cases, you may have irreducible retroversion, or at least irreducible pelvic gestation. I am not aware that any serious results have been caused by this operation. It was suggested by William Hunter, and a case was reported in 1830 by Mr. Baynham. The real nature of the case was not ascertained for six weeks, the cathetcr only being used night and morning. Even when the bladder was empty, the uterus rested every attempt to return it. The most prominent part of the tumour in the rectum was punctured with a trocar, and about twelve ounces of liquor amnii, without blood, were drawn off. Reduction followed in about fifteen minutes. A full opiate was given. The foetus was expelled twenty-five hours after the operation. The patient recovered. In this case, the puncture was made through the rectum, and no doubt the place is very convenient; but the puncture may be made through the vagina by perforating the posterior wall. One point you must bear in mind if you puncture by the vagina, and that is, to noint the trocar perpendicnlarly to the uterine wall. For this purpose, the trocar must be directed obliquelyr backwards toward the upper part of the hollow of the sacrum. If you direct the point forwards, you will run the instrument obliquely in the uterine wall, perhaps towards the cervix, and whilst wounding an unnecessary extent of structure, you may miss the cavity of the ampion. The liquor amnii being evacuated, a considerable collapse of the uterus will take place. You may now rest awhile. It is not advisable immediately to use any force in renewed attempts to reduce the uterus. Its lessened bulk will no longer entail the dangers that threatened before. The process of lessening the bulk of the uterus which you have begun will be further carried out by nature in two ways. First, abortion, expulsion of the foetus and secundines will follow; and this effected, the process of involntion sets in by which the muscular tissue is rapidly diminished. This done, there is a spontaneous termination to the affection.

T have but a few words to say concerning the general treat ment. To relieve pain and spasm, opium and chloroform are the most useful means. The system, which is apt to give way and be prostrated, must be sedulously supported by stimulants and nourishment. To meet the danger of uræmic poisoning, I would recommend nitro-hydrochloric acid and ether.

\section{A REPORT OF \\ TWO CASES IN WHICH THE KNEE-JOINT WAS EXCTSED.}

By P. C. PRICE, EsQ., M.R.C.S.,

SURGEON TO THE GRYAT NORTHERN HOSPITAL, THE METROROLITAN TASTITUTION FOR SCROFULOUS CHILDRNA AT MIARGATE, ETC.

SINCE the publication of my small memoir relating to excision of diseased knee-joints, I have reason to believe that the operation has been practised by various surgeons with greater confidence, while attention to some features of practical import has enabled less experienced operators to surmount many supposed obstacles in the subsequent treatment of the limb. Within the past few months I have twice resorted to the operation; and, as I conceive the details of every case in which the proceeding has been employed in preference to am. putation to be worthy of special notice, I shall briefly record the most interesting facts connected with both instances.

CASE 1.--Phœbe $\mathbf{R}$ - - a naturally delicate girl, thirteen years of age, was admitted into the Metropolitan Institution for Scrofulous Children at Miargate on July 3rd, 1858, on account of old-standing disease of the right knee-joint, complicated with the exhibition of more or less general strnmous symptoms. During the earlier part of the time she was at Margate, the bowels discharged a muco-purulent fluid nixed with the evacuations. Under suitable treatment this condition subsided, and the child gradually gained flesh and health.

The right knee-joint then attracted chief attention. Al acute mischief had ceased, but considerable annoyance was still experienced from occasional pain. Pressure over some parts of the articulation gave rise to still greater pain, while any attempt to flex or extend the lower limb was accompanied with feelings of dread. The original cause of the mischief was obscure. The disease had existed for nearly five years, and curing that period the integrity of the joint had been almost entirely destroyed. The tibia had become dislocated behind the condyles of the emur. The patella had anchylosed itself to the anterior surface of the femur. Various fistulous sinuses had allowed the escape of portions of bone from the femur, which, immediately bove the condyles, was thinner and more irregular in shape than natural. Very considerable consolidation had taken place from the effusion of lymph around and behind the joint. The hamstring tendons were strougly contracted. The calf of the leg had not decreased to any very appreciable amount, and the muscles appeared healthy. The leg was flexed at nearly a right angle to the thigh, and some slight motion could be detected.

The girl, seeing the useful legs that I had preserved to two of her companions by removing the destroyed articulation of the knee, was very anxious to have some operation performed which would enable her to throw away her crutch and gain the use of her limb.

On the 16th of April, Dr. Rowe having placed her under chloroform, with the assistance of my friends, Messrs. Hunter, Hoffman, and Thornton, and my brother, Dr. W. P. Price, (to whose kind assistance I have many times been indebted, I endeavoured, by using considerable force, to break down any adhesions which might be retaining the leg in its abnormal position, but to no purpose. I also freely divided all the hamstring tendons, but still the head of the tibia conld not be bronght into any lind of correct apposition with the condyles of the femur.

In preference to amputation, I removed the joint, which was accomplished in the way $I$ an in the habit of performing the operation. Abont two inches of the end of the femur were at lirst removed, but it was found necessary to re-apply the saw and take away another thin slice of bone, in order to avoid any bruisinc of the cancellated structure, when obtaining precise apposition of the cut bony surfaces. In the portion corresponding to the external condyle was discovered a small cavity, lined with a thick, velvety membrane, which communicated with the interior of the articulation. Merely the articular surface of the tibia was remored, which at once showed that the osseous tissue was apparently quite healthy. The synovial membrane was not much altered in structure, but the articular cartilages were vlcerated in spots. The patella was removed, though, to all appearance, bealthy.

The surfaces of the bones came admirably into apposition, and the limb, while the child was still under chloroform, was placed upon the splint $I$ am in the habit of using.

Little or no shock followed the operation and the child progressed well for three weeks. At the end of a month I hoped to change the iron splint for one of gutta percha, but, alas! my most sanguine anticipations of the perfect success of the operation were doomed to disappointment. The flap of skin covering the ends of the bones, which had united to its adjacent parts by first intention, at the end of the fifth week showed syinptoms of ulceration; and, in a few days, a hole, about the size of a slilling, allowed the outer surface of the end of the femur to be exposed. Prior to this, there had been absence of all pain; now, however, there was tenderness along the tract of the saphenous vein, extending up as high as the iliac veins. Hectic, loss of appetite, and emaciation proclaimed that the internal lesion, suspected by the pain in the right side, was exercising a very depressing influence on the entire system. Poultices and hot fomentations to the wound and along the course of the affected venous canals certainly afforded, for a day or two, some hopes that the nntoward symptoms were subsiding. Liberal quantities of stimulants were administered, together with iarge doses of morphia. Quinine and the mineral acids, for a short period, created a desire for food, but the stomach was too irritable to allow its retention for any time.

On the 31st of May, seven weeks from the date of operation, all the unfavourable symptoms were increased in severity. In addition, the wound was sloughy, and although the ends of the bones were lkept in perfect apposition, still the upper surface of the femur corresponding to the slough in the skin was black and apparently destroyed. The tenderness in the right side had increased, while the old discharge of muco-purulent matter from the bowels became constant, accompanied by excessive diarrhœa, which was with difficulty stopped.

On the 8 th of June, the discharge from the bowels had become more copiots and strictly purulent. The amount of 
union between the divided ends of the bones, which appeared to have progressed rapilly during the first four weeks, was now broken up, and the wound discharged a sanious, semipurulent fluid. A few days later, a large abscess formed in the site of the right hip-joint, but its occurrence created but little pain. It was quite astounding to see how tenacious the whole system was of life. Little or no nourishment was taken voluntarily, and the child remained in a most listless condition. With the utmost care and attention on the part of my brother, Dr. W. P. Price, who most skilfully managed the daily requirements of the case, the little patient was sustained, with a fluttering hope on his part that some amendment might take place, but unfortunately death occurred on the lst of July, seventy-six days from the date of operation.

No post-mortem examination was obtained, but the portions of bone immediately included in the wound were removed. Their surfaces were dark-coloured, and to all appearance had been dead for some time. The cut plane of the tibia was studded with small portions of new bone, showing that reparation had advanced to some extent; indeed, my brother had formed an opinion, at the end of the first month, that considerable union had cemented the parts.

During the treatment, the limb was removed from the splint only once, and not till after the seventh week. The absence of all local irritation from constant movement, as is too often practised, was thereby avoided, and much suffering saved the patient.

My disappointment at the non-success of the operation in this instance I confess was great, as I had every reason before, and for some weeks after its performance, to believe that it would be in every respect successful.

CAsE 2.-On the lst of June last was admitted into the Great Northern Hospital, under my care, a man aged twentysix. He was sent from Yeovil, in Somersetshire, by Mr. Garland, under whose treatment he had been for some time.

The following is the history given by the patient of his case: About four years since the left knee-joint suddenly commenced to swell, and became very painful. Under the influence of suitable remedies, as the local application of iodine, \&o., the articulation resumed its proper size, but still some desree of pain told that the mischief was not quite eradicated. After having been at his work (that of a labourer) for a few weeks, he was compelled to desist, and again sought advice and rest for the aching limb. At various periods during two years he was enabled to do some work, but was often obliged to take to his bed at the occurrence of erery fresh attack of swelling and pain. In September, 1853, he fell down and struck the unfortunate knee, which reignited the slumbering mischief, and com pelled him to place himself in the hands of his surgeon. He remained in bed for two weeks ; but since the date of the accident has never been enabled to follow his employment. Three weeks before his admission all the symptoms of extensive dis organization of the articulation had fairly proclaimed the necessity of some definite interference.

After remaining in the hospital for a few alays-recovering from the fatigue incident to the journey he had made-the fol. lowing local symptoms were noted:-The shape of the joint is much altered. There is apparent displacement of the tibia and fibula behind the condyles of the femur. The patella is moved outwards from the median line. The form of the joint is more or less irregularly globular, and there exists some considerable swelling over the heal of the tibia. The pain is constant, but accelerated at night, when it becomes more gnawing in character, and gives rise from its intensity to sleepless nights and cold clammy sweats. The slightest manipulation causes increased pain, and the rreatest tenderness is felt when pressure is male over the patella. The man has no power to move his limb without using both hands; but the slightest jerking gives rise to a fit of agony.

The general health from continued suffering is fast giving way. Naturally delicate, and exhibiting a tendency to scrofulous affection, it was feared that his lungs might be in a critical state, but no cough had made its appearance. The virtues of opium and morphia had long lost their effect upon him, and, as he gradually found his strength failing, he prayed that some defnite operation might be resorted to, as blistering, moxa, \&c., had all been futile in relieving the pain and mischief. Prior, however, to parforming any definite operation, I applied the actual cautery freely to the joint, and placed the man on a liberal diet.

On the 11 th of June, ten days after his admission, at midnight, he was seized with a sudden fit of coughing, and brought up a few ounces of blood. This was repeated on the day following, and also on the 15th. Under the influence of large doses of gallic and sulphuric acids with opium, any further recurrence was prevented.

A careful stethoscopic examination was made by my colleagues, Drs. Leared and Cholmeley, and a certain amount of crepitation was detected beneath the right clavicle. There was also well-marked dullness over the upper portion of the right lung, occupying a space about thrice the size of a crown-piece. The untowarl event greatly alarmed the patient, and he did not recover his composure for some few days.

On the 25th Dr. Cholmeley advised counter-irritation over the right side of the chest, with croton oil, which produced a well-marked effect. The crepitation lessened, and the dullness became less distinct.

The man continued to improve in health, but constant pain in the knee and its severe effect upon the constitution not succumbing, I was induced to decide upon the propriety of removing a source of irritation which, within a few months, would prove, in all probability, the cause of an untimely end.

$I$ have been called upon, on more than one occasion, to perform capital operations when, to all appearance, the constitution was in every way unfitted to withstand many of the extra demands which might be made upon it. In two instances-an excision of the head of the femur and an amputation through the middle of the thigh-I was particularly struck with the beneficial results which immediately followed. Instead of an ulcerating process, accompanied with pain -and pain of such a character as to induce great depression-night-sweats, loss of appetite, and diarrhca, a clean wound exists, which nature boldly endeavours to heal by processes painless and normal

Considering the condition of the patient, I had no hesitation whatever in resorting to an operation to relieve him of all his formidable symptoms. In selecting between amputation and excision of the vitiated joint, there was, in my own mind, no difficulty. I believe if ain excision be well managed in all its details from first to last, few surgeons who have had an opportunity of performing both operations on several occasions will find even a loop-hole for doubt.

On the 7 th of July, the patient appeared in a condition to stand the immediate shock of an operation; and, when under the influence of chloroform, I removed the diseased joint. Care was taken not to reflect any diseased tissues with the skin and its connecting cellular membrane. The joint was irretrievably destroyed. Scarcely a vestige of investing cartilage remained on either femur or tibia. The bones, in some parts, were deeply ulcerated, while the synovial membrane was pulpy, velvety, and greatly altered in structure. Purulent fluid existed in the joint cavity, in lieu of synovia. About two inches -were removed from the end of the femur, and about a half to three quarters of an inch from the tibia. The patella, entirely deprived of its cartilage, was likewise taken away.

The bones, when cut with the saw, exhibited all the appearances of health; and I placed the parts in apposition, con fident, if no very untoward symptoms occurred, that the result would answer my most sanguine anticipations. More arterial bleeding than usual, perhaps, took place; but this is a feature which betokens health, and promises a fulfilment of the re sources of Nature to create repair in healthy structures. Before removing the man from the operating table, the limb was adjusted on the usual splint; but I did not venture to fasten the reflected flap of skin to its adjacent parts, thinking that, owing to the somewhat excessive vascularity of the bones, some secondary hæmorrhage might, perchance, occur. Silver sutures were, however, inserted through the parts, so that the flap might be fastened, when expedient, without putting the man to any extra pain. I have lately found it more convenient to adjust the limb to the splint before closing the wound, as the surfaces of the bones are brought into apposition with a greater certainty. This is a feature, though trivial, worth remember ing, as ocular proof is thereby afforded of the correct position of the opposing surfaces.

The relief afforded by the operation was most marked. The very first night refreshing sleep was obtained, and not once during the treatment did the patient complain of any untoward symptom. The flesh-wound united by first intention, except at the sides, which were kept patent to give exit to the discharge. The amount of suppuration was comparatively trivial. After the first week, the man began to gain flesh rapidly, the cough ceased, and the night-sweats entirely dis appeared. Thanks to Mr. Evans, the excellent house-surgeon, the patient was most carefully watched. The limb was not moved from the splint till the seventh week, when a guttapercha support was substituted for the more cumbrous one of metal. Bony union was quite complete, and the man could raise and twist his limb in every direction. Improved in 
bodily health, and rid of a serious local disease, the patient left the hospital on the eighth week from the day of operation, in a condition soon to resume his employment, and but slightly mutilated.

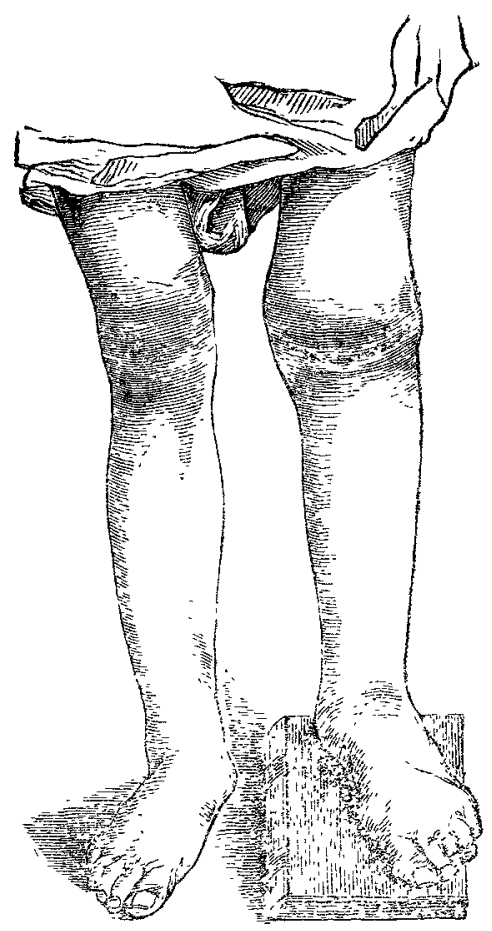

The accompanying woodcut, excctly representing the condition of the limb eight weeks after removal of the joint, was taken by Dr. Westmacott. The swelling of the lower limb, and the slightly-puffy condition of the parts immediately in volved in the operation, are truthfully represented.

I look upon the result, in this case, with feelings of great satisfaction, and regard it as a marked triumph for conservative surgery. It is the opinion of many of my colleagues, as well as my own, that had amputation through the thigh been adopted, instead of the less formflable operation of excision, the man would have stood a less chance of recovery; indeed, T have reason to know that amputation of the limb had been seriously considered, but that those who consulted about its propriety, before his arrival in London, had refused to operate, thinking that the patient's state of health was in too shattered a condition to admit of its performance.

Green-street, Grosvenor-square, Nov. 1859.

\section{REPORT OF A CASE OF}

\section{PARALYSIS AGITANS REMOVED BY THE CONTINUOUS GALVANIC CURRENT.}

\section{By J. RUSSELL REYNOLDS, M.D. LOND., F.R.C.P.,} ASSISTANT-PHYSICIAN TO THE WESTMINSTER HOSPITAL,

W. F- male, aged fifty-seven; married at the age of twenty, and the father of twelve children; height, $5 \mathrm{ft} .10 \frac{1}{2} \mathrm{in.}$; weight, under 11 st. No anatomical deformity; no hereditary predisposition to disease; has had good health; has lived well and temperately. His occupation is that of a carpenter; he has resided in a healthy locality, and has never, until the commencement of his present illness, suffered from anything of a similar kind.

For the last five years he has had anxiety with regard to his children, and distress at parting from them, but he cannot definitely refer his malady to this cause. During the last two years he has noticed occasional tremor of the right arm and leg, the latter being affected less frequently and less severely than the former. The tremor has occurred if he (1) has been "put out about anything;" (2) has attempted to lift anything very heavy; (3) has "taken cold ;" (4) has lifted liquid in a cup to the mouth; or (5) has fully extended the arm and forearm, and pressed anything firmly with the palm of the hand. But under all these circumstances the tremor has ceased when the "exciting cause" has been removed, and it has never been so severe as to prevent him, from following his occupation, which is one requiring much exertion and accurate direction of movements

For the last six or eight months he has suffered occasional vertigo-i, e,, a "feeling as if he should fall, or pitch on his head; and as if the head were tied up in tight bandages." At the same time there has been darting pain through the head.

On September 20th he was at work as usual-was alternately stooping down and lifting over his head-when he suddenly felt vertigo, aching in knee-joints, and general disturbance; and at the same time violent shaking occurred in the right upper extremity. The agitation of the right arm continued througbout the day, but stopped at night. It returned on the following morning, as soon as he moved.

On October 5 th he was first seen by myself, and on this day (the fifteenth from its commencement) the agitation was ex. treme. Nevertheless, it had always ceased during the night; and, on two occasions, for about an hour, and without assignable cause, during the day. He thinks it is arrested at night by pressing the anterior surface of the forearm against the crest of the ilium. With the exceptions above mentioned, the movements of the arm have been much the same as now seen; being occasionally aggravated, but not much, by emotional disturbances, or by the attempt at voluntary movement of the extremity.

The whole of the right upper limb is involved-i. e., the hand moves on the forearm, the forearm on the arm, the arm on the shoulder; but the most constant and most extensive movement is that at the elbow-joint; the least constant and least extensive is that at the shoulder. Almost every direction of movement possible in the upper extremity is performed; from 22 to 24 double movements occur in five seconds, and the range of movement at the hand, when, for example, the jerking is principally that of fiexion and extension of the forearm, varies from nine to ten inches. The movement, therefore, amounts to about eight feet per second.

To the patient himself the right arm feels hotter than the left, and a difference of temperature is very obvious to the hand of the observer. Temperature over left biceps, $87^{\circ}$ Fahr.; over right, $91^{\circ}$.

The involuntary movement of the arm can be arrested by his lying on the sofa, and pressing the forearm against the ilium; but any attempt to move the limb voluntarily at once reproduces the shaking, although he remains in the recumbent posture. The movement is, moreover, instantly arrested by my firmly grasping either the forearm in any part of its upper two thirds, or the arm in its lower third. This is not a mere mechanical arrest of the movements, for it cannot be effected by holding the wrist; and the jerking recommences if, while the extremity is grasped in the manner described, the patient makes any attempt at a voluntary movement. The pressure is not painful, nor is it so directed as to arrest the circulation.

The mental condition of the patient, and his general health, appear unaffected.

Sensibility is unchanged in the right upper extremity; there is no deviation of the tongue, nor distortion of the features. He can walk well, and without dragging either leg; there is only occasionally slight tremor of the right leg.

A continuous galvanic current (direct) was applied to the arm and forearm, the movements of the latter being at the time arrested by pressure. At the end of five minutes he could execute voluntary movements without the least tremor, and emotional excitement failed to reproduce the jerking. The temperature of the two arms, examined after the current had been passing for half an hour, was equal. The involuntary movements did not return until three hours after the current was discontinued; they then reappeared, and continued through. out the evening; stopped at night, but returred on the follow. ing morning.

October 6th. - The current was applied while the arm was in violent movement, but in two minutes it became perfectly still. Application continuer for an hour.

7th. - Last evening there was no jerking nor tremor for five hours after the current was discontinued; then it commenced, but stopped spontaneously in about half an hour, and during the remainder of the evening there was nothing more than very trifling tremor. The jerking has returned this morning, but is much less than on the first day of observation. There are but twenty alternations in fifteen seconds, and the range of movement is from three to four inches. The movement therefore, is only 86 foot per second-less than one-eightn of what it was three days ago.

The current was applied on the 7 th, on the 8 th, and 10 th $_{3}$. and after the 10th-i. e., after five applications, - the sponta. 